\title{
News and Events
}

The Jerusalem Seminar in Architecture

21-23 June 1998

Information: Lynne R. Rosman, The Jerusalem Seminar in Architecture

Tel: 97225639047 . Fax: 97225610028

E-mail: jersemar@netvision.net.il

\section{Fourth International Conference on Urban History \\ 3-5 August 1998; Venice \\ Call for session on 'The European City: Places and Institutions' \\ Information: no contact details}

NATAU'98 Architecture and Urban Design: Technologies for the XXI Century 8-11 September 1998; Sao Paulo, Brazil

Information: Conference Secretariat NATAU, Rua do Anfiteatro 181, Colmeia Favo 6, Cidade
Universitaria, Sao Paulo, SP CEP 05508-900, Brazil

Tel/Fax: +55118183209

ECLAS Conference: Urban landscapes and city regions

The European city as a resource for landscape teaching and research

17-20 September 1998; Vienna

Information: ECLAS 98, Wien Kongressburo, TU Wien, Institut fur Landschaftsplanung und Gartenkunst, Karlsgasse 11, A-1040 Wien

Eighth Congresso Iberoamericano de Urbanismo. Reestruturacao Urbana e Coesao Territorial 21-24 September 1998; Porto, Portugal

Information: Secretaria permanente, Av. da Boavista, 1586-2-Sala 304, 4100 Porto, Portugal

Tel: +351 26095196/6003702. Fax: 35126003634 